\title{
Theoretical Study of Particle Dissolution during Homogenization in $\mathrm{Cu}-\mathrm{Fe}-\mathrm{P}$ Alloy
}

\author{
Spyros Papaefthymiou ${ }^{1, *(1)}$, Marianthi Bouzouni ${ }^{1,2}$ and Evangelos Gavalas ${ }^{1,2}$ (]) \\ 1 Laboratory of Physical Metallurgy, Division of Metallurgy and Materials, School of Mining \& Metallurgical \\ Engineering, National Technical University of Athens, 9, Her. Polytechniou str., Zografos, \\ 15780 Athens, Greece; mbouzouni@elkeme.vionet.gr (M.B.); egavalas@elkeme.vionet.gr (E.G.) \\ 2 Department of Physical Metallurgy and Forming, Hellenic Research Centre for Metals S.A.-ELKEME S.A., \\ 56th km Athens-Lamia Nat. Road, 32011 Oinofyta, Greece \\ * Correspondence: spapaef@metal.ntua.gr; Tel.: +30-210-772-4710
}

Received: 18 May 2018; Accepted: 12 June 2018; Published: 14 June 2018

\begin{abstract}
The effect of temperature, soaking time and particle size on the dissolution of particles $\left(\mathrm{Fe}_{3} \mathrm{P}\right.$ and $\left.\mathrm{Fe}\right)$ during homogenization was simulated employing Thermocalc ${ }^{\circledR}$ and DICTRA software. The initial precipitate size was determined through metallographic evaluation on industrial as-cast $\mathrm{Cu}-\mathrm{Fe}-\mathrm{P}$ alloy. The particle sizes vary from submicron $(<1 \mu \mathrm{m})$ up to $10 \mu \mathrm{m}$ before the heat treatment. As homogenization temperature rises, the dissolution rate increases as well, but only on temperatures above $1273 \mathrm{~K}\left(1000^{\circ} \mathrm{C}\right)$ is the rate capable of completely dissolving particles effectively. At temperatures above $1273 \mathrm{~K}\left(1000{ }^{\circ} \mathrm{C}\right)$, precipitates with sizes below $5 \mu \mathrm{m}$ dissolve completely into the $\mathrm{Cu}$ matrix, while larger particles only slightly decrease their size. Particles at enriched copper areas remain undissolved and slightly increase their size which is attributed to micro segregation and the local change of equilibrium conditions. The simulation results are in agreement with homogenization trials at lab scale.
\end{abstract}

Keywords: $\mathrm{Cu}-\mathrm{Fe}-\mathrm{P}$; dissolution; diffusion; homogenization; heat treatment; $\mathrm{Fe}_{3} \mathrm{P}$; Fe particles; solid solution

\section{Introduction}

The increased requirements for economic copper $(\mathrm{Cu})$ tubes being able to withstand higher pressures while working in extreme service environments and maintain their conductivity have led to research around a number of Cu-based alloys with higher mechanical properties. The endeavor to increase the mechanical properties of solid solution hardened alloys is limited by their insufficient relaxation resistance at slightly increased temperatures and decreasing electrical and thermal conductivity when heavily alloyed. To overcome this, the focus has turned to precipitation-hardened alloys $[1,2]$. Recently, copper-iron-phosphorus $(\mathrm{Cu}-\mathrm{Fe}-\mathrm{P})$ alloys have been a successful medium-strength and high-conductivity alternative that provide superior properties over other widely used materials for copper tubes, such as deoxidized-high-phosphorus (DHP) copper [3].

The industrial application and the effects of thermomechanical processing on the microstructure and second-phase particles have been studied in [4-6]. The improvement of the mechanical properties in $\mathrm{Cu}-\mathrm{Fe}-\mathrm{P}$ alloys is attributed to precipitation hardening via fine dispersion of particles $(\alpha-\mathrm{Fe}, \gamma-\mathrm{Fe}$, $\left.\mathrm{Fe}_{3} \mathrm{P}\right)$ in the $\mathrm{Cu}$ matrix and the materials' resistance to softening due to recrystallization $[2,4,5,7,8]$.

In $\mathrm{Cu}-\mathrm{Fe}-\mathrm{P}$ alloys, small-sized particles (submicron scale), found at the grain boundaries, are desirable in the microstructure as they control recrystallization and pin grain boundaries and dislocations via the Zener drag mechanism [4,5,9], thereby limiting grain growth. Coarse particles should be avoided as they do not pin dislocations and grain boundaries during recrystallization which 
results in reduced mechanical properties and material sensitivity at high temperatures. Homogeneous distribution of fine particles is of great importance and is achieved via appropriate precipitation heat treatment, which consists of homogenization, quenching and aging. During homogenization, the temperature must be high enough to induce the dissolution of particles. This procedure is followed by quenching in which the cooling rate must prevent any diffusion and precipitation, and ensure that the copper $(\mathrm{Cu})$ matrix is supersaturated with phosphorous $(\mathrm{P})$ and iron $(\mathrm{Fe})$ atoms. Finally, during the aging treatment the required driving force is provided for the supersaturated matrix to reach equilibrium. So, fine particles begin to form homogeneously. The size of phosphides depends on the temperature and time for aging and not on the final cooling rate [10].

Since the properties of $\mathrm{Cu}-\mathrm{Fe}-\mathrm{P}$ alloys are greatly influenced by microalloying, each production step has to be carefully designed to achieve the required final properties. Many researchers have applied various methods to optimize mechanical and material (i.e., thermal conductivity, microstructure, etc.) properties. Extensive investigation has been held on the influence of various alloying elements (e.g., $\mathrm{Ni}, \mathrm{Si}, \mathrm{Mg}, \mathrm{Mn}$ ) and their concentration on the $\mathrm{Cu}$ matrix [6,11-15]. $\mathrm{Lu}$ et al. [11] showed that traces of boron B and cerium Ce could increase the recrystallization temperature, succeeding more complete aging and, thus, obtaining the strengthening effect via work and precipitation hardening. Brovč et al. [12] and Yamamoto et al. [13,14] indicated the high potential of $\mathrm{Cu}-\mathrm{Fe}-\mathrm{Ni}-\mathrm{P}$ alloy, illustrating the good conductivity and mechanical properties at elevated temperatures, as an alternative economic alloy, in order to avoid the addition of toxic (i.e., Cd, Be) or precious metals (e.g., Ag) used until now as alloying elements in the industry. The addition of $\mathrm{Mg}$, $\mathrm{Si}$, $\mathrm{Pb}$ and $\mathrm{Mn}$ further improve the mechanical properties of the alloy without compromising conductivity when carefully used [6,15].

Since the results of annealing at the final stages of copper tube production, where recrystallization and aging takes place, have as a prerequisite an efficient homogenization at the beginning of the production process, the dissolution of $\mathrm{Fe}$ and $\mathrm{Fe}_{3} \mathrm{P}$ particles during homogenization is of great importance. Particle dissolution theory initially introduced by Whelan [16], describes the solute flux in conjunction with the particle size and concentrations. The diffusional growth and dissolution has been studied extensively in terms of interface movement and diffusion of solute atoms in iron systems [17-19]. However, little work has been done on non-ferrous alloys.

Although both the alloying and the ageing treatment have been thoroughly studied, the homogenization step has not been adequately investigated. Several homogenization strategies have been implemented industrially and many researchers have analyzed the effect of temperature and time on homogenization annealing, using only material characterization techniques but without explaining the criteria of the optimal homogenization and specifying the optimal conditions for a successful homogenization $[4,7,11,12]$. Parameters are difficult to be determined and are very important for industrial production, where time and sizes impose limitations.

For this purpose, homogenization experiments were simulated with the aid of Thermocalc ${ }^{\circledR}$ and DICTRA software at various temperatures and soaking times in order to understand the influence of the process conditions and the local chemical composition on the Fe-rich particle dissolution. The results have been compared to experimental data in order to determine the homogenization behavior of $\mathrm{Cu}-\mathrm{Fe}-\mathrm{P}$ alloy.

\section{Material and Modelling}

The chemical composition of an industrially produced billet with a diameter of $600 \mathrm{~mm}$ is shown in Table 1, which complies with BS EN 12449:2012 standard [20]. The Thermocalc ${ }^{\circledR}$ (Version 2018a, Thermo-Calc Software AB, Solna, Sweden) calculation of the alloy's phase diagram, utilizing the CALculation of PHAse Diagrams-CALPHAD method, has been deployed in order to predict the phases formed in crucial temperature areas and determine the temperature window for the homogenization process. Through metallographic evaluation, the different sizes of precipitates were measured and used as input data for the simulation. For the simulation of homogenization, three phases 
were considered: $\mathrm{Fe}, \mathrm{Fe}_{3} \mathrm{P}$ and $\mathrm{Cu}$ matrix. The system was limited to $\mathrm{Cu}-\mathrm{Fe}-\mathrm{P}-\mathrm{Zn}$. The alloy's solidification was simulated in DICTRA (Version 2018a, Thermo-Calc Software AB, Solna, Sweden) with a cooling rate $10 \mathrm{~K} / \mathrm{s}$ in order to predict the chemical composition of the $\mathrm{Cu}$ matrix (Table 2).

Table 1. Alloy's composition.

\begin{tabular}{cccc}
\hline Fe (\%) & P (\%) & Zn (\%) & Cu (\%) \\
\hline 2.3 & 0.025 & 0.12 & 97.555 \\
\hline
\end{tabular}

Table 2. Composition of $\mathrm{Cu}$ matrix in alloying element-depleted regions.

\begin{tabular}{ccc}
\hline Fe (\%) & P (\%) & Zn (\%) \\
\hline 1.8 & 0.01 & 0.1291 \\
\hline
\end{tabular}

The activation enthalpies were set at $250,000 \mathrm{~J} / \mathrm{mol}$ and $210,000 \mathrm{~J} / \mathrm{mol}$ respectively determined by Thermocalc. Similar values for the activation enthalpy can be found elsewhere [21].

The effect of segregation upon homogenization was taken into account in this study as it greatly affects the homogenization result. Thus, additional simulations were carried out for particles dissolving in an alloying element-enriched $\mathrm{Cu}$ matrix whose chemical composition is shown in Table 3. The chemical composition was defined by Thermocalc ${ }^{\circledR}$ considering that the segregated zones obtain the chemical composition of the $\mathrm{Cu}$ matrix at the beginning of the solidification, as given in Table 3.

Table 3. Composition of $\mathrm{Cu}$ matrix in alloying element-enriched regions.

\begin{tabular}{ccc}
\hline Fe (\%) & P (\%) & Zn (\%) \\
\hline 3.8 & 0.025 & 0.15 \\
\hline
\end{tabular}

In Figure 1 the particle distribution in the initial microstructure before homogenization is illustrated. The particles are spherical or quasi-spherical, thus the system has been modeled with spherical particle of predefined size $\left(D_{\mathrm{p}}\right)$ surrounded by copper matrix with a radius of $100 \mu \mathrm{m}$, as depicted in Figure 2. The radius of the matrix refers to the sample's average grain size; however, the influenced area was studied in order to ensure that there is no interaction between two neighboring particles of the same size. The initial particle size of $\mathrm{Fe}_{3} \mathrm{P}$ particles was selected to be 1, 5, 7 and $10 \mu \mathrm{m}$ and of the Fe particles $1 \mu \mathrm{m}$ with spherical geometry, respectively, based on metallographic results.

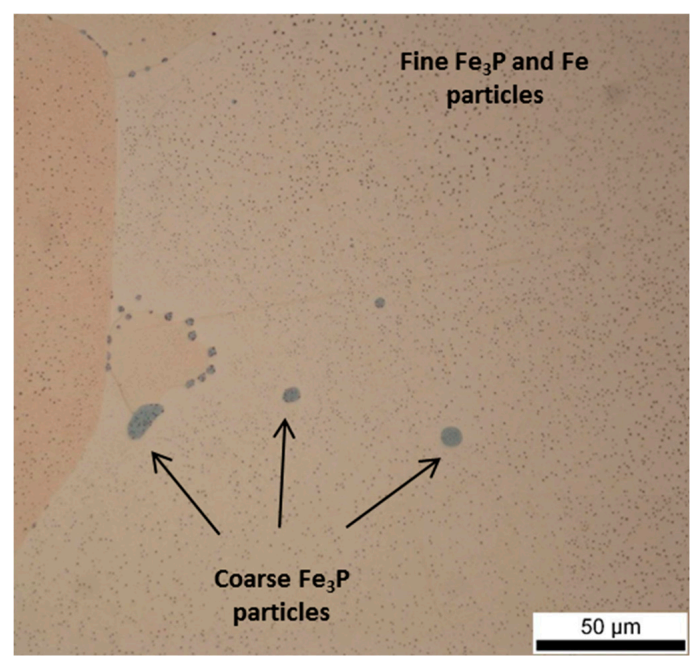

Figure 1. Microstructure of $\mathrm{Cu}-\mathrm{Fe}-\mathrm{P}$ alloy. $\mathrm{Fe}_{3} \mathrm{P}$ particles appear with size ranging from 1-10 $\mu \mathrm{m}$ preferably at grain boundaries whereas Fe particles are homogeneously distributed in the $\mathrm{Cu}$ matrix. 


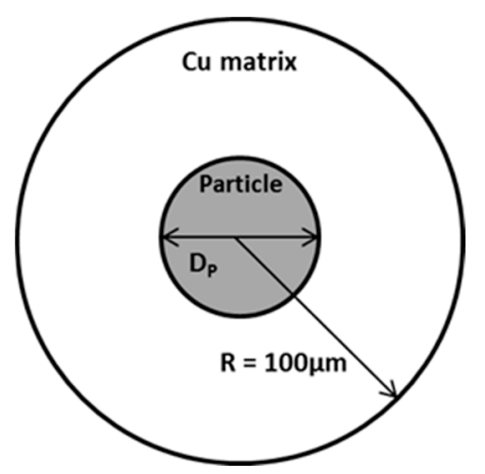

Figure 2. Schematic representation of the system used for DICTRA calculations. The $D_{\mathrm{P}}$ obtains values $1 \mu \mathrm{m}, 5 \mu \mathrm{m}, 7 \mu \mathrm{m}, 10 \mu \mathrm{m}$.

Two sets of simulations for each individual particle were held at the following temperatures: $1073 \mathrm{~K}\left(800{ }^{\circ} \mathrm{C}\right), 1173\left(900^{\circ} \mathrm{C}\right)$ and $1273 \mathrm{~K}\left(1000^{\circ} \mathrm{C}\right)$. In the first set, particle dissolution took place in the alloying element-depleted $\mathrm{Cu}$ matrix (Table 2), and in the second set dissolution simulations took place in the alloying element-enriched $\mathrm{Cu}$ matrix (Table 3). The temperature of $1073 \mathrm{~K}\left(800{ }^{\circ} \mathrm{C}\right)$ was defined as the lowest temperature that the billet can be extruded in an industrial extrusion press. The maximum soaking time selected for the homogenization simulations was $10 \mathrm{~h}$. The heating rate used to reach the homogenization temperature was $1 \mathrm{~K} / \mathrm{s}$. An estimate of the mobility expression [21] of Fe and $\mathrm{P}$ for the $\mathrm{Fe}_{3} \mathrm{P}$ and Fe particle was made,

$$
M=\frac{M^{o}}{R T} \exp \left(\frac{-Q}{R T}\right)
$$

in which $M^{\circ}$ is the frequency factor, $Q$ the activation enthalpy, $R$ is the constant for gas and $T$ is the temperature. Calculations were performed using DICTRA software and the databases TCCU1 and MOBCU1 assuming that local equilibrium exists at interfaces [22].

\section{Modelling Results}

\subsection{Phase Diagram}

The calculated isopleth sections of phase diagrams of the $\mathrm{Cu}-\mathrm{Fe}-\mathrm{P}$ alloy in thermodynamic equilibrium are illustrated in Figures 3 and 4. The diagrams show that the phases that exist at equilibrium are liquid, $\mathrm{Cu}$ (matrix), $\gamma-\mathrm{Fe}, \alpha-\mathrm{Fe}$ and $\mathrm{Fe}_{3} \mathrm{P}$ while the red lines denote the examined alloy's chemical composition also indicated in Table 1. $\mathrm{Fe}_{3} \mathrm{P}$ and $\alpha$-Fe precipitates form in temperatures below $973-1230 \mathrm{~K}\left(700-957^{\circ} \mathrm{C}\right)$ depending on the local chemical composition. The influence of the $\mathrm{Fe}$ and $\mathrm{P}$ on the phase diagram has been studied as well in order to understand the influence of local chemical composition variation. By increasing Fe concentration, the $\mathrm{Fe}_{3} \mathrm{P}$ dissolution threshold temperature slightly decreases by $\sim 30 \mathrm{~K}$ in the range from $2.1 \% \mathrm{Fe}$ to $2.6 \% \mathrm{Fe}$, as shown in Figure 3 . However, $\mathrm{P}$ plays a more important role as depicted in Figure 4. By increasing $\mathrm{P}$ concentration from $0.015 \% \mathrm{P}$ to $0.05 \% \mathrm{P}$, the $\mathrm{Fe}_{3} \mathrm{P}$ dissolution temperature increases from $843 \mathrm{~K}\left(570{ }^{\circ} \mathrm{C}\right)$ to $1033 \mathrm{~K}\left(760^{\circ} \mathrm{C}\right)$. The liquid temperature is not influenced by chemical composition variation of Fe and $\mathrm{P}$. 


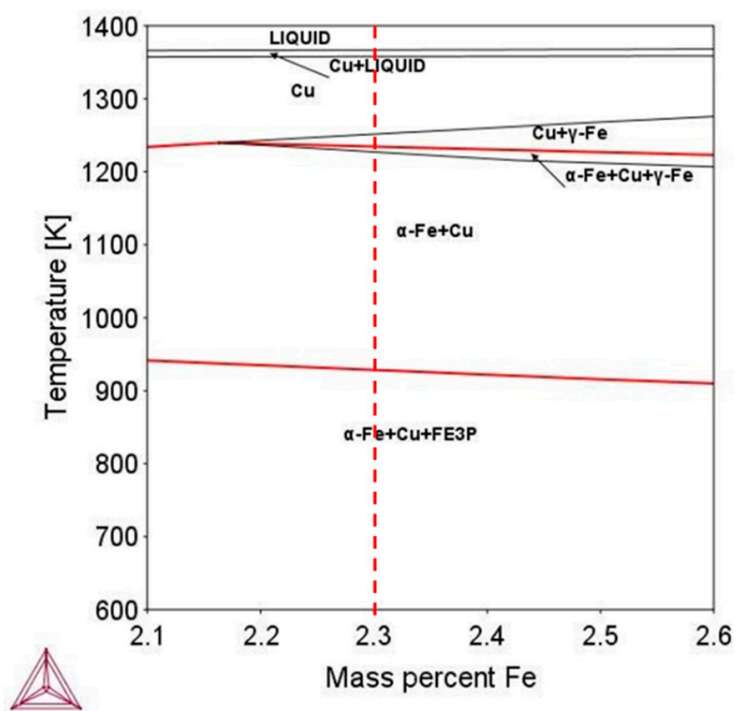

Figure 3. Isopleth section of $\mathrm{CuFe}_{2} \mathrm{P}$ alloy phase diagram-Fe dependency. The red lines show the temperatures at which $\alpha-\mathrm{Fe}$ and $\mathrm{Fe}_{3} \mathrm{P}$ particles are formed depending on Fe content.

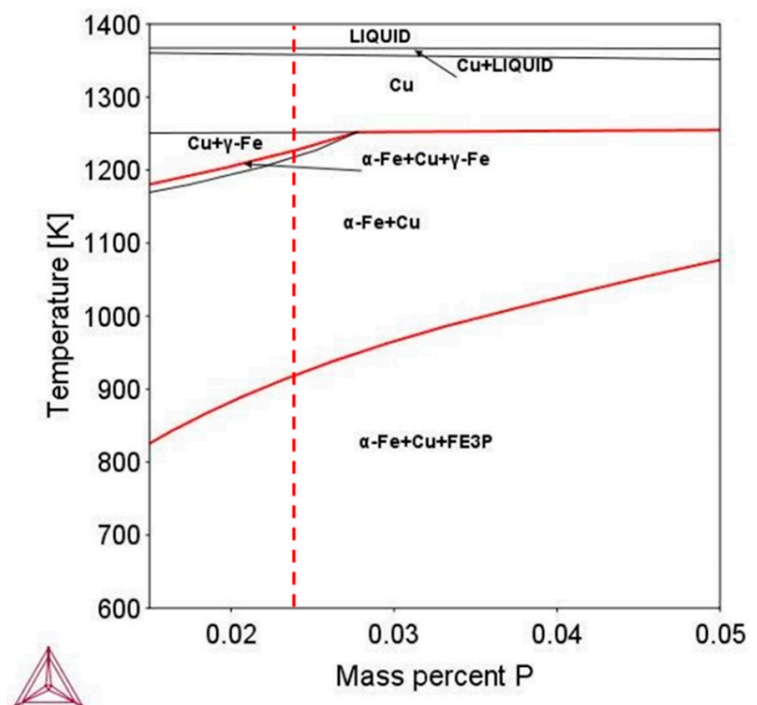

Figure 4. Isopleth section of $\mathrm{CuFe}_{2} \mathrm{P}$ alloy phase diagram $-\mathrm{P}$ dependency. The red lines show the temperatures at which $\alpha$-Fe and $\mathrm{Fe}_{3} \mathrm{P}$ particles are formed depending on $\mathrm{P}$ content.

\subsection{Dissolution Calculations}

In Figures 5-7 the particle size evolution during homogenization, in both alloying element depleted and enriched regions, is illustrated for various initial particle diameters and different soaking temperatures.

At $1073 \mathrm{~K}\left(800^{\circ} \mathrm{C}\right)$ the graphs remain almost parallel to the abscissa axis at the depleted matrix simulations. According to the phase diagrams (Figures 3 and 4), although it is thermodynamically feasible to perform homogenization at the temperature of $1073 \mathrm{~K}\left(800{ }^{\circ} \mathrm{C}\right)$, since it is higher than the dissolution threshold temperature, practically there is no phosphide size alteration for the given time. The low temperature limits the diffusion rate which in turn deteriorates the particle dissolution (Figure 5). 

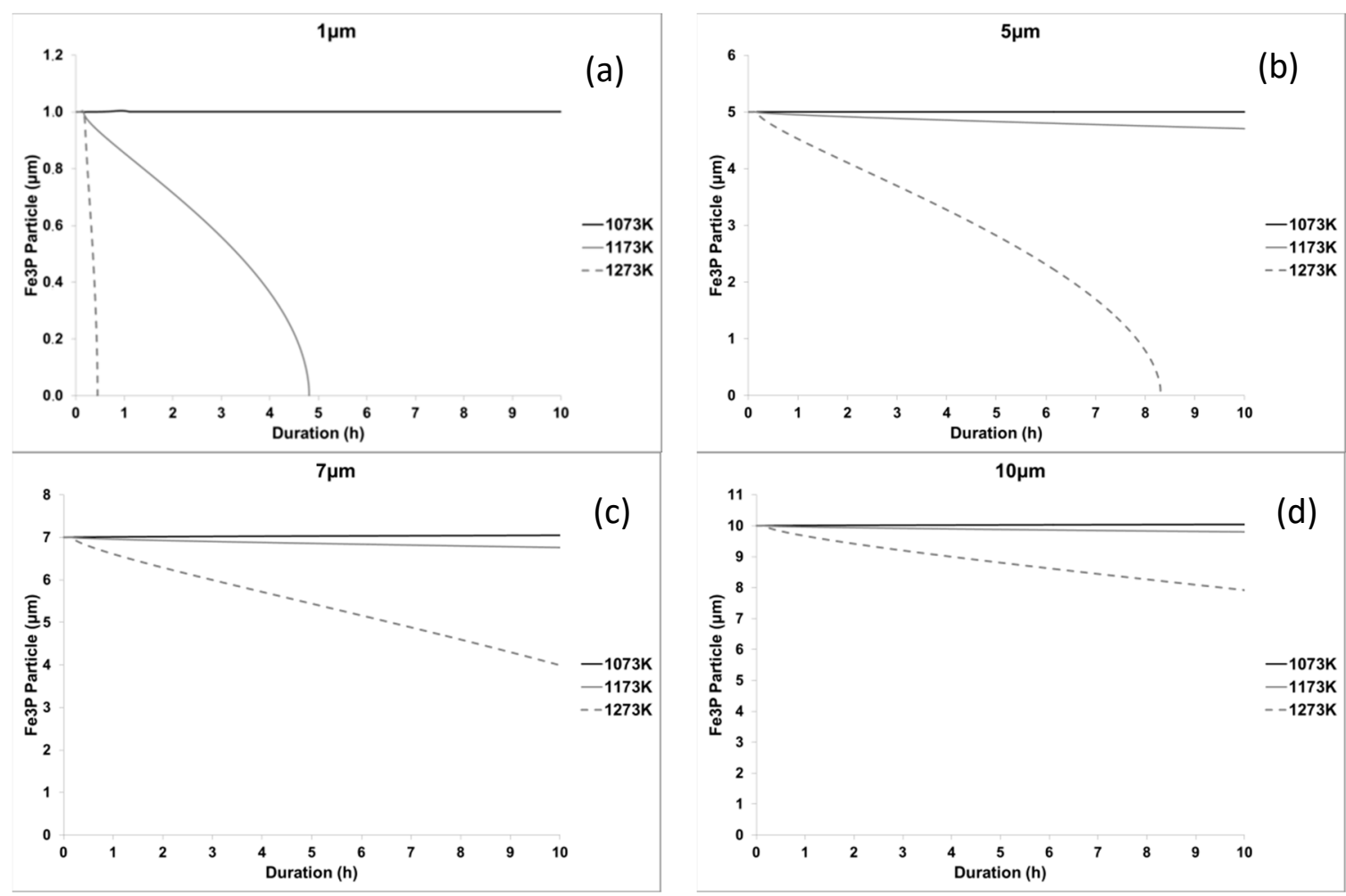

Figure 5. Simulation results of homogenization of $\mathrm{Fe}_{3} \mathrm{P}$ particles in the $\mathrm{Cu}$ matrix tested at various temperatures for (a) $1 \mu \mathrm{m}$, (b) $5 \mu \mathrm{m}$, (c) $7 \mu \mathrm{m}$, (d) $10 \mu \mathrm{m}$.
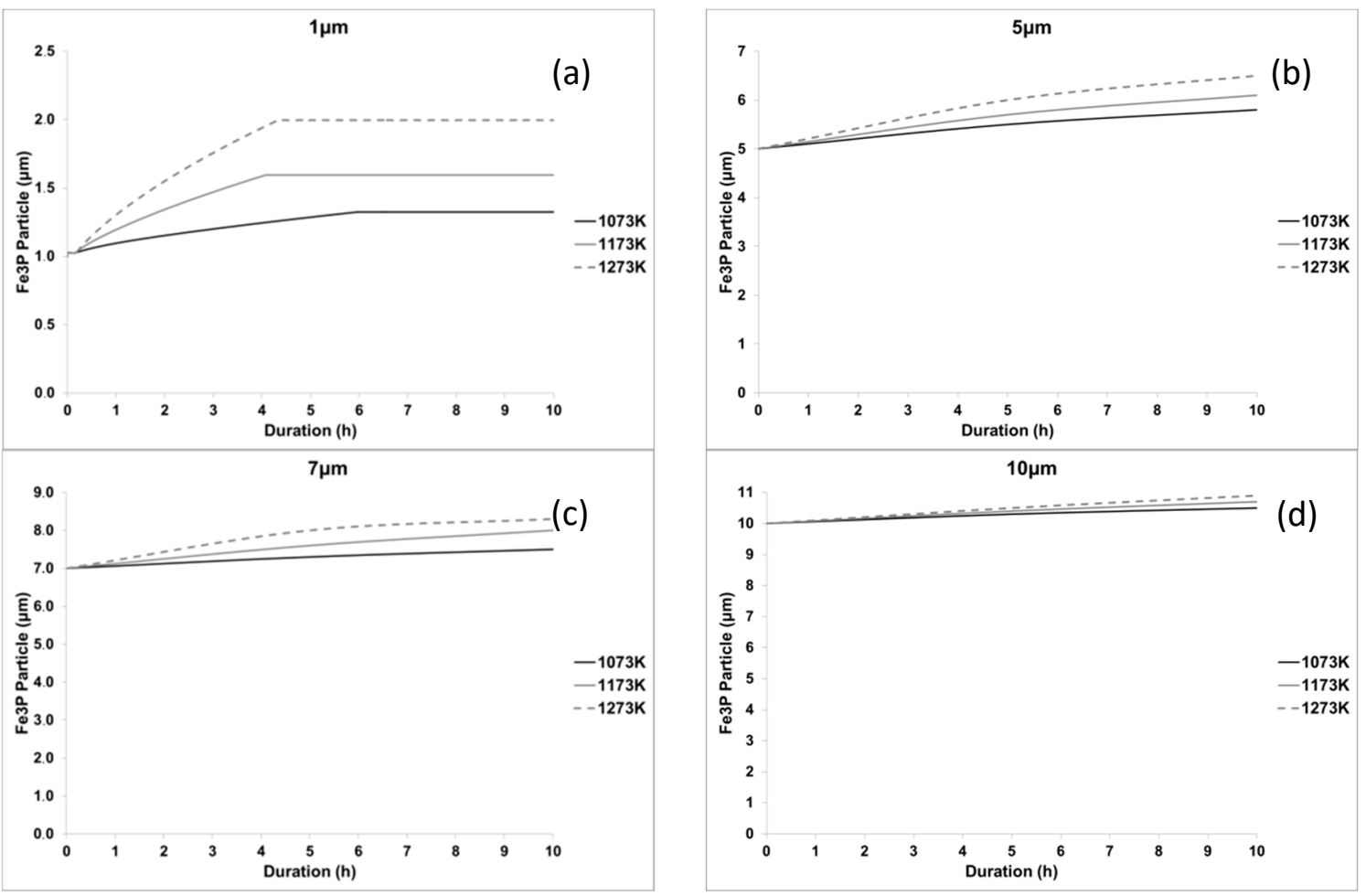

Figure 6. Simulation results of homogenization of $\mathrm{Fe}_{3} \mathrm{P}$ particles in an enriched $\mathrm{Cu}$ matrix tested at various temperatures for (a) $1 \mu \mathrm{m}$, (b) $5 \mu \mathrm{m}$, (c) $7 \mu \mathrm{m}$, (d) $10 \mu \mathrm{m}$. 

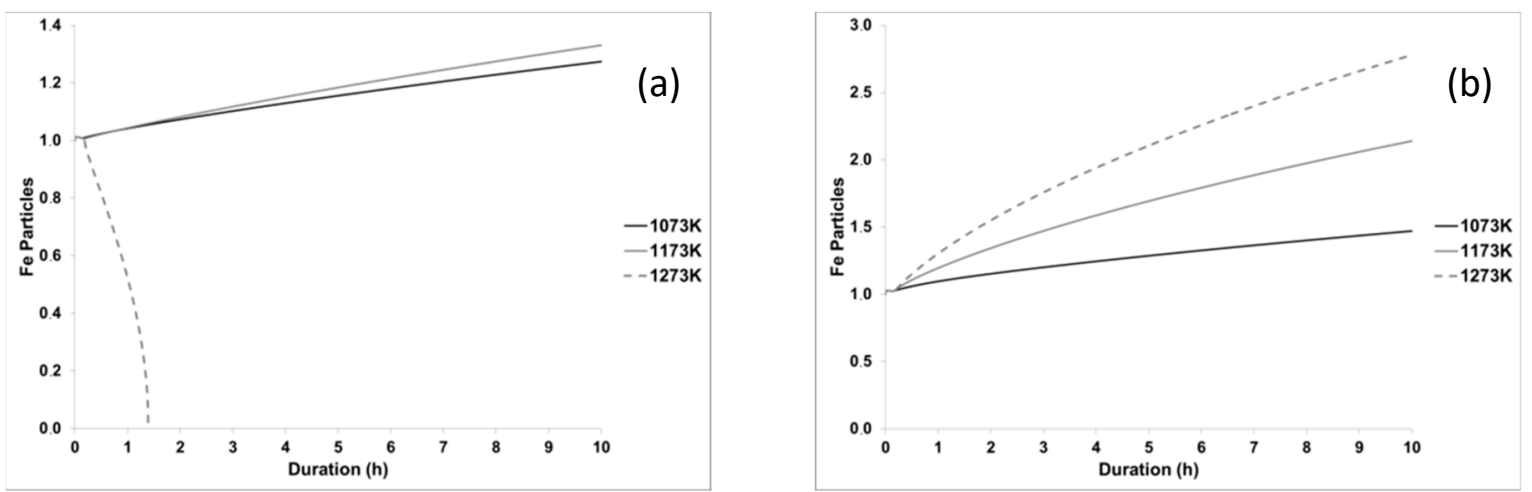

Figure 7. Simulation results of homogenization for Fe particles tested at various temperatures for (a) depleted copper matrix in Fe and $\mathrm{P}(\mathbf{b})$ enriched copper matrix in Fe and $\mathrm{P}$.

By increasing the temperature, the diffusion rate increases as well for all particle sizes. Complete dissolution of small size $\mathrm{Fe}_{3} \mathrm{P}$ particles $(1 \mu \mathrm{m})$ is evident from the temperature of $1173 \mathrm{~K}\left(900{ }^{\circ} \mathrm{C}\right)$ within the experimental homogenization duration (Figure 5a). However, particle size influences the dissolution rate notably. $\mathrm{Fe}_{3} \mathrm{P}$ particles with initial size of $5 \mu \mathrm{m}$ could not dissolve in temperatures below $1173 \mathrm{~K}\left(900{ }^{\circ} \mathrm{C}\right)$ (Figure $5 \mathrm{~b}$ ), while $\mathrm{Fe}_{3} \mathrm{P}$ particles with $7 \mu \mathrm{m}$ initial size require even higher temperature $\sim 1223 \mathrm{~K}\left(\sim 950^{\circ} \mathrm{C}\right)$ (Figure $\left.5 \mathrm{c}\right)$. Large $\mathrm{Fe}_{3} \mathrm{P}$ particles $(10 \mu \mathrm{m})$ do not dissolve even at $1273 \mathrm{~K}$ $\left(1000{ }^{\circ} \mathrm{C}\right)$ within the $10 \mathrm{~h}$ soaking time (Figure $5 \mathrm{~d}$ ).

The homogenization duration time is also an important factor. Small size particles $(1 \mu \mathrm{m})$ require from almost $10 \mathrm{~h}$ at temperature of $1073 \mathrm{~K}\left(800{ }^{\circ} \mathrm{C}\right)$ to only few minutes as the temperature rises to $1273 \mathrm{~K}\left(1000{ }^{\circ} \mathrm{C}\right)$ (Figures $5 \mathrm{a}$ and $\left.7 \mathrm{a}\right)$. The larger particles $(7 \mu \mathrm{m}, 10 \mu \mathrm{m})$, although undissolved, slightly reduce their size by increasing temperature until $1273 \mathrm{~K}\left(1000^{\circ} \mathrm{C}\right)$ (Figure $\left.5 \mathrm{c}, \mathrm{d}\right)$.

The surrounding copper matrix also significantly affects the particle dissolution. In regions enriched in alloying elements, the particles not only remain undissolved but increase their size (Figures 6 and 7) as the copper matrix is supersaturated.

As a particle dissolves, the surrounding area is enriched in alloying elements. The influenced area around a dissolving particle is smaller than half of the distance between two neighboring particles of the same size, which indicates that there is no interaction between them. A representative illustration of the influenced area can be seen in Figure 8. The Fe concentration of the surrounding region of a dissolving $1 \mu \mathrm{m}(R=0.5 \mu \mathrm{m})$ particle, exactly the moment that complete dissolution is realized, suggests that the Fe concentration reaches the nominal concentration of the $\mathrm{Cu}$ matrix only $2.5 \mu \mathrm{m}$ away from the initial position of the particle-matrix interface. 


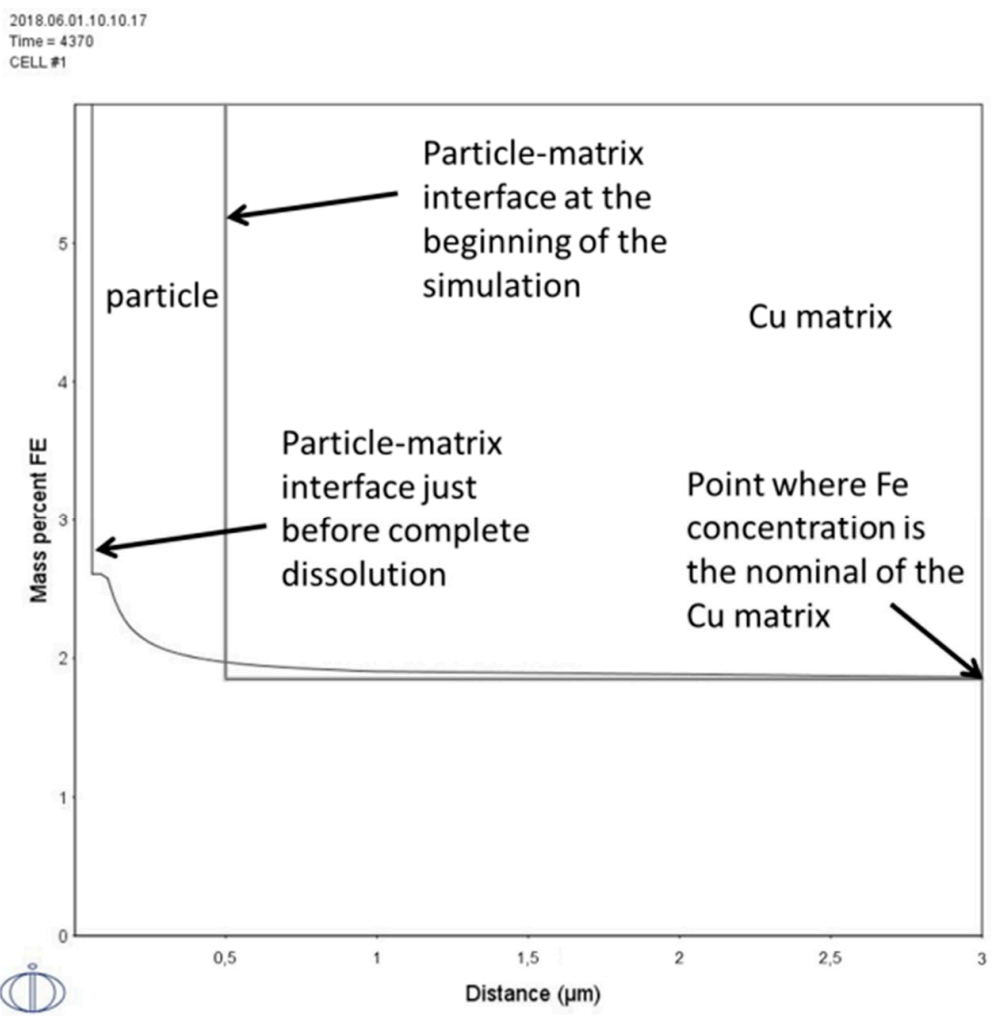

Figure 8. Fe concentration around a $1 \mu \mathrm{m}(R=0.5 \mu \mathrm{m})$ particle at the beginning and the end of the dissolution process.

\section{Homogenization Trials}

Specimens from the center of an industrially produced billet, with a diameter of $600 \mathrm{~mm}$, were obtained and homogenized at $1273 \mathrm{~K}\left(1000^{\circ} \mathrm{C}\right)$ for $10 \mathrm{~h}$ and then water quenched. The metallographic evaluations, illustrated in Figure 9, are in good correlation with the simulation results. A significant number of small particles $(\sim 1 \mu \mathrm{m})$ were dissolved whereas elliptical Fe particles with increased size and coarse spherical $\mathrm{Fe}_{3} \mathrm{P}$ particles were apparent in the microstructure. Scanning electron microscopy-energy dispersive X-ray spectroscopy (SEM-EDS) (Philips XL40 sfeg, Amsterdam, Netherlands) analysis indicates that the spherical particles are $\mathrm{Fe}_{3} \mathrm{P}$ particles since the $\mathrm{Fe} / \mathrm{P}$ analogy is $\sim 3$ whereas the elliptical/rod like particles are Fe particles (Figure 10).

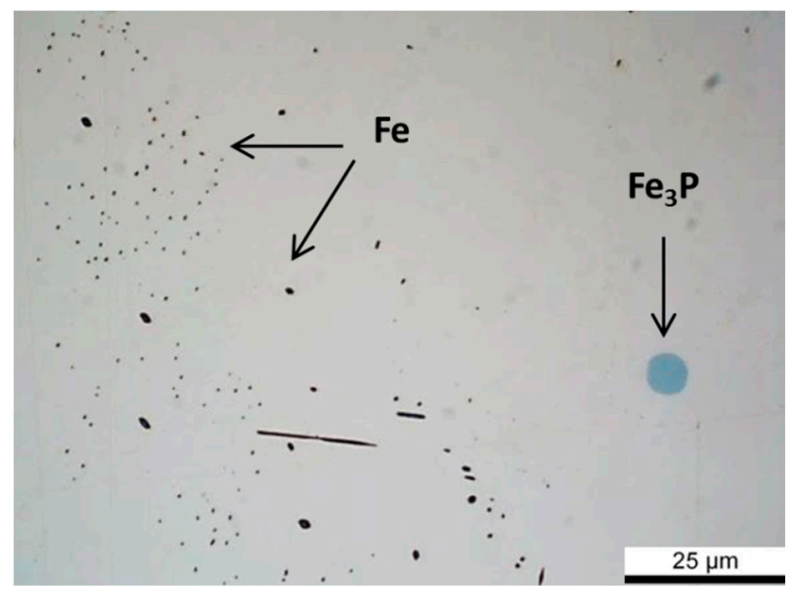

Figure 9. Microstructure of $\mathrm{Cu}-\mathrm{Fe}-\mathrm{P}$ alloy after homogenization. The majority of submicron particles are dissolved. Coarse $\mathrm{Fe}_{3} \mathrm{P}$ particles remain undissolved while Fe particles with increased size appear. 


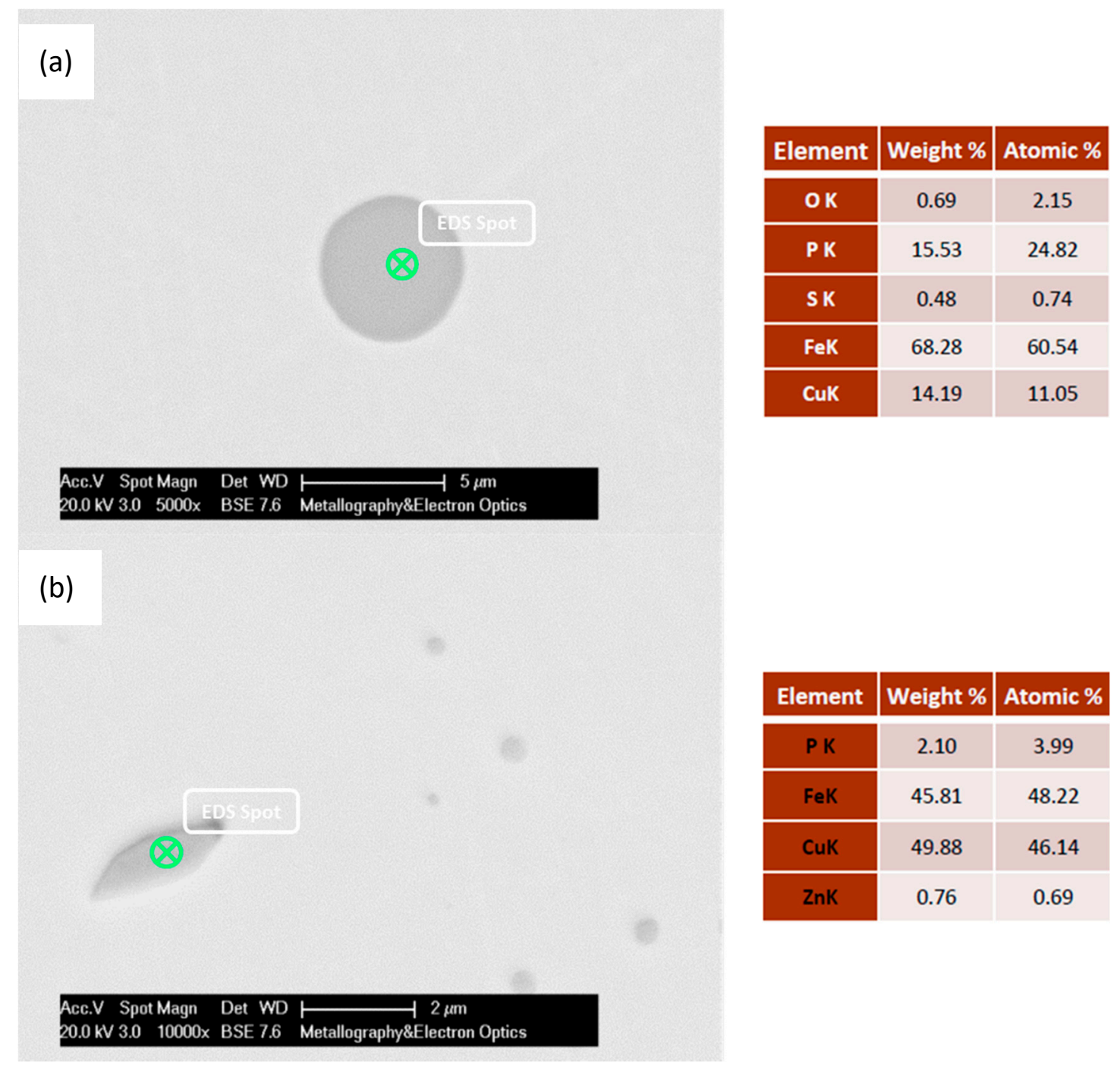

Figure 10. Scanning electron microscopy-energy dispersive X-ray spectroscopy (SEM-EDS) analysis on the intermetallic particles (a) spherical $\mathrm{Fe}_{3} \mathrm{P}$ particle, (b) elliptical Fe enriched particle. The arrow indicates where the chemical analysis was taken.

\section{Discussion}

Intermetallic particle size can greatly vary depending on the production conditions of the examined sample. A laboratory specimen is ideally produced in clean conditions with controlled cooling and casting speed. By contrast, in industrially produced billets due to centerline segregation and slow cooling rates the amount of larger-sized particles found in the billet's center is increased and, consequently, this is the most insensitive area during the homogenization process in terms of particle dissolution. This causes inhomogeneity across the billet's thickness. A different thermodynamic equilibrium applies to the center of the billet compared to conditions at the outer surface due to different alloying element concentration (Figure 4). An important criterion for the decision of homogenization temperature and time is the initial microstructure of the processed sample.

The process window for an industrially produced billet lies in the high temperature range for $1.5-2 \mathrm{~h}$. From the results it can be observed that mainly the small particles in high temperature simulations were dissolved, requiring less than two hours for this purpose. Any further time results in no further dissolution and in some cases in particle growth, possible defects and additional production cost. A homogenization anneal at the low-temperature range will have almost no effect on the material. 
The duration of homogenization can vary from a few minutes to many hours even for small-sized particles $(1-5 \mu \mathrm{m})$ at temperatures in which $\mathrm{Fe}_{3} \mathrm{P}$ particles should have been dissolved $\left(\sim 800^{\circ} \mathrm{C}\right)$ according to the phase diagram. Since the $\mathrm{Cu}$ matrix is not in equilibrium but filled with alloying elements in solid solution, the diffusion rate decreases, restricting the particle dissolution.

Although small particles were successfully dissolved, large particles were still found in the microstructure after the homogenization, as expected after the simulation. However, it is obvious that there are regions with increased large particle concentration. As can be seen from the phase diagrams (Figures 3 and 4), in the case of $\mathrm{P}$, increased local concentration, due to excessive segregation, dramatically increases the dissolution temperature and stabilizes the phosphide particles making the dissolution even more difficult. Moreover, copper regions enriched in alloying elements are supersaturated and it is difficult for Fe to diffuse and, therefore, it remains in solid solution in the $\mathrm{Cu}$ matrix. Figure 11 shows the concentration profile of $\mathrm{Fe}$ at the Fe particle/Cu matrix interface. $C_{\beta}$ is the Fe concentration in the Fe particle as expected by equilibrium, whereas $C_{\alpha}$ is the Fe concentration in $\mathrm{Cu}$ matrix at equilibrium. $C_{o}$ is the Fe content of the supersaturated $\mathrm{Cu}$ matrix. When $C_{\alpha}<C_{o}$, it means that the Fe content has to reach the $C_{\alpha}$ composition in the $\mathrm{Cu}$ matrix, thus, there is a flux of $\mathrm{Fe}$ atoms from the matrix towards the Fe particle and diffusional growth can be achieved. When $C_{\alpha}>C_{0}$, this indicates that the Fe content in the $\mathrm{Cu}$ matrix should reach $C_{\alpha}$ composition. In order to achieve this, Fe atoms diffuse from the Fe particle towards $\mathrm{Cu}$ matrix and the dissolution of Fe particles can be achieved. The different solubility of particles and $\mathrm{Cu}$ matrix is attributed to the chemical composition and crystal structure. $\mathrm{Fe}_{3} \mathrm{P}$ and $\mathrm{Fe}$ particles were considered to have a BCC (body centered cubic) structure whereas the $\mathrm{Cu}$ matrix has an FCC (face centered cubic) structure. The flux of solute atoms towards the interface is described by an error function introduced by Whelan [16]. The diffusional distance that the atoms have to move $\Delta x$ can be calculated from, the overall concentration of mass is given by Equation (2) for isothermal transformation [23]:

$$
\left(C_{\beta}-C_{o}\right) x=\frac{1}{2}\left(C_{o}-C_{a}\right) \Delta x
$$

where $C$ stands for concentration and $x$ for particle size.
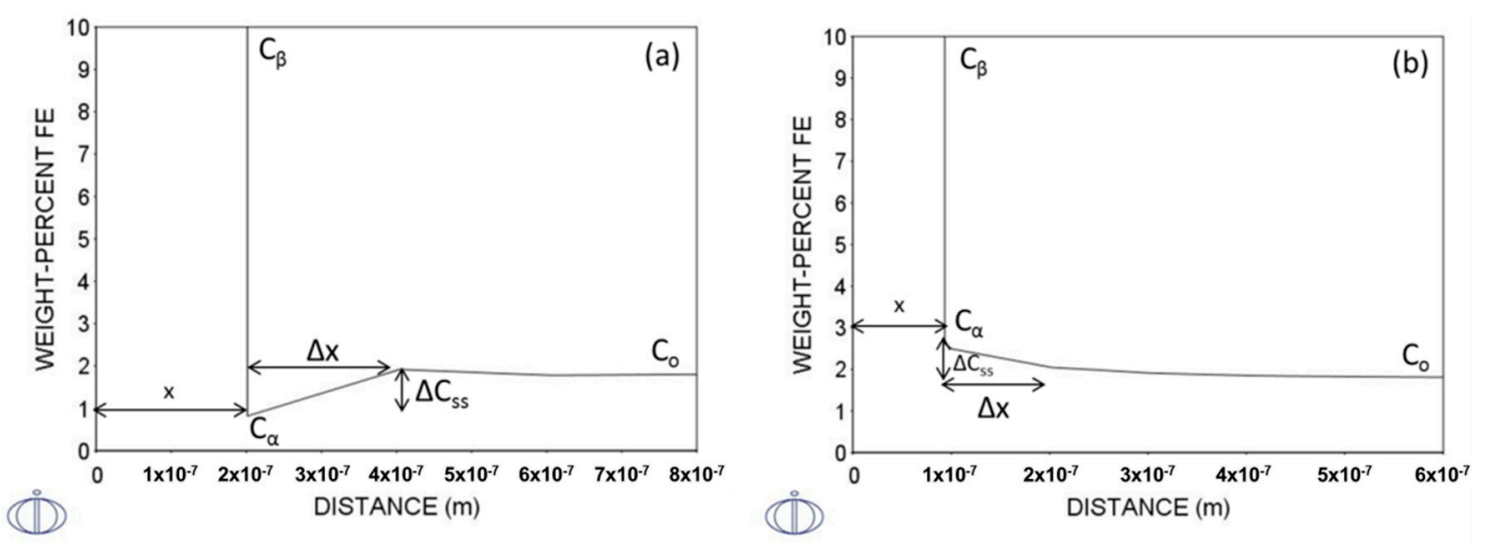

Figure 11. Plot of Fe profiles versus $\mathrm{Cu}$ matrix (a) growth of Fe particles, (b) dissolution of Fe particles. The diagrams are concentrated on the interface thus $C_{\beta}$ is $90 \mathrm{wt}$ \%.

It can be observed that in alloying element-enriched regions, particles had even increased their size. The increase of particle size can also be explained from the Ostwald ripening theory where large particles are more energetically stable than smaller particles. Atoms of the small particles diffuse and attach to the large particles resulting in large particles growing in size and small particles shrinking [24]. 


\section{Conclusions}

Particle dissolution has been investigated during the homogenization process in a $\mathrm{Cu}-\mathrm{Fe}-\mathrm{P}$ alloy via Thermocalc ${ }^{\circledR}$ and DICTRA software. The phase diagrams indicate that the iron mass percentage does not influence the dissolution temperature. However, higher phosphorus concentration stabilizes the $\mathrm{Fe}_{3} \mathrm{P}$ loop and increases the dissolution temperature. According to the simulation results, the particle dissolution depends on four critical parameters influencing each other: (a) the size of phosphides; (b) soaking time; (c) the temperature of homogenization; and (d) the local chemical composition of the base metal. In alloying element-depleted regions dissolution was realized in approximately $1 \mathrm{~h}$ for the small particles of $1 \mu \mathrm{m}$ in the temperature of $1273 \mathrm{~K}\left(1000^{\circ} \mathrm{C}\right)$. Larger particles are more difficult, requiring longer, or are even impossible to dissolve. Chemical heterogeneity due to segregation caused local phenomena of a higher element concentration in the base metal, resulting in particles either remaining undissolved or in many cases increasing in size due to the Ostwald ripening phenomena. Metallographic evaluation showed that the experiments are consistent with the simulation. Microsegregation is evident in the initial microstructure situated mainly in grain boundaries and interdendritic regions. The homogenization heat treatment created in the microstructure patches of precipitation-free regions and other regions with a small number of enlarged particles due to a different local chemical equilibrium.

For the optimal homogenization of the specific material, a high temperature of $1273 \mathrm{~K}\left(1000{ }^{\circ} \mathrm{C}\right)$ is required. Homogenization time of 1.5-2 $\mathrm{h}$ will result in the dissolution of the small particles without affecting the larger ones. Longer soaking time will result in no further dissolution.

Author Contributions: Conceptualization, S.P.; Methodology, S.P., E.G. and M.B.; Validation, E.G., M.B. and S.P.; Writing-Original Draft Preparation, M.B.; Writing-Review and Editing, S.P. \& E.G.; Supervision, S.P.; Project Administration, E.G.

Funding: This research received no external funding.

Acknowledgments: The authors express their gratitude to the Hellenic Research Centre for Metals-ELKEME S.A., the R\&D company VIOHALCO S.A., for their overall support to this research. The authors sincerely thank Athanasios Vazdirvanidis and Alexandros Antonopoulos for carrying out SEM and OM.

Conflicts of Interest: The authors declare no conflict of interest.

\section{References}

1. Pawlek, F.; Reichel, K. Der Einfluss von Beimengungen auf die elektrische Leitfähigkeit von Kupfer. Z. Met. 1956, 47, 347-356.

2. Zauter, R.; Kudashov, D.V. Precipitation hardened high copper alloys for connector pins made of wire. In Proceedings of the 23rd International Conference on Electrical Contacts ICEC2006/Sendai, Sendai, Japan, 6-9 June 2006.

3. Pantazopoulos, G.; Toulfatzis, A.; Zormalia, S.; Vazdirvanidis, A.; Skarmoutsos, D. Preliminary evaluation of the thermally affected metallurgical condition of extruded and drawn $\mathrm{CuFe}_{2} \mathrm{P}$ tubes. J. Mater. Eng. Perform. 2012, 21, 2188-2194. [CrossRef]

4. $\quad$ Dong, Q.-Y.; Shen, L.-N.; Wang, M.-P.; Jia, Y.-L.; Li, Z.; Cao, F.; Chen, C. Microstructure and properties of $\mathrm{Cu}-2.3 \mathrm{Fe}-0.03 \mathrm{P}$ alloy during thermomechanical treatments. Trans. Nonferrous Metals Soc. China 2015, 25, 1551-1558. [CrossRef]

5. Cao, H.; Min, J.Y.; Wu, S.D.; Xian, A.P.; Shang, J.K. Re-precipitation of coherent $\gamma$-Fe particles following annealing of equal channel angular pressed Cu-Fe alloy. Mater. Sci. Eng. A 2006, 431, 86-91. [CrossRef]

6. Taro, K.; Motohisa, M.; Kenjyu, M.; Mitsuhiro, O.; Ryoichi, O.; Akinori, T. Corrosion resistant copper alloy tube and fin-tube heat exchanger. European Patent 0626459A1, 27 May 1994.

7. Kim, H.G.; Han, S.Z.; Euh, K.; Lim, S.H. Effects of C addition and thermo-mechanical treatments on microstructures and properties of Cu-Fe-P alloys. Mater. Sci. Eng. A 2011, 530, 652-658. [CrossRef]

8. Ammannati, N. Method for the production of alloy pipes for heat exchangers using precipitation hardening through underwater extrusion. EP 2027947B1 European Patent Specification, 6 April 2011. 
9. Smith, S.C. Grains, phases, and interfaces: An interpretation of microstructure. Metall. Mater. Trans. B 1948, $175,15-51$.

10. Callister, W.D., Jr.; David, G.R. Materials Science and Engineering, 9th ed.; Wiley: Hoboken, NJ, USA, 2014.

11. Lu, D.P.; Wang, J.; Zeng, W.J.; Liu, Y.; Lu, L.; Sun, B.D. Study on high-strength and high-conductivity Cu-Fe-P alloys. Mater. Sci. Eng. A 2006, 421, 254-259. [CrossRef]

12. Brovc, G.; Drazic, G.; Karpe, B.; Djordjevic, I.; Lojen, G.; Kosec, B.; Bizjak, M. Synthesis and characterization of hardened Cu-Fe-Ni-P alloy. Metalurgija 2015, 54, 51-54.

13. Yanamoto, Y.; Sasaki, G.; Yamakawa, K.; Ota, M. Tokio: Hitachi Cable Review; No. 19; The Technical Journal of Hitachi Cable: Tokyo, Japan, 2000.

14. Yamamoto, Y.; Takano, H.; Ohta, M.; Tong, C.; Kunishige, A. Tokio: Hitachi Cable Review; No. 26; The Technical Journal of Hitachi Cable: Tokyo, Japan, 2007.

15. Ohashi, Y.; Fujino, T.; Taki, Y.; Nishijima, T. Aged Copper Alloy with Iron and Phosphorous. U.S. Patent 5,071,494, 10 December 1991.

16. Whelan, M.J. On the kinetics of precipitate dissolution. Metal Sci. J. 2013. [CrossRef]

17. Voice, W.E.; Faulkner, R.G. Computer simulated dissolution of carbide precipitates in alloys. Metal Sci. 1984, 18, 411-418. [CrossRef]

18. Liu, Z.K.; Höglund, L.; Jönsson, B.; Ågren, J. An experimental and theoretical study of cementite dissolution in an Fe-Cr-C alloy. Metall. Trans. A 1991, 22. [CrossRef]

19. Liu, Z.K.; Agren, J. Morphology of cementite decomposition in an Fe-Cr-C alloy. Metall. Trans. A 1991, 22, 1753-1759. [CrossRef]

20. Davis, J.R. Copper and copper alloys-Seamless, round tubes for general purposes. In BSI Standards Limited 2012: The British Standards Institution; ASM International: Geauga County, OH, USA, 2012.

21. Butrymowicz, D.B.; Manning, J.R. Michael R. Diffusion in copper and copper alloys. Part III. Diffusion in systems involving elements of the groups IA, IIA, IIIB, IVB, VB, VIB, and VIIB. J. Phys. Chem. Ref. Data 1975. [CrossRef]

22. Borgenstam, A.; Engstrom, A.; Hoglund, L.; Agren, J. Dictra, a tool for simulation of diffusional transformations in alloys. J. Phase Equilib. 2000, 21, 269-280. [CrossRef]

23. Bhadeshia, H.K.D.H. Course MP6, Kinetics and Microstructure Modelling. Available online: https: / / www. phase-trans.msm.cam.ac.uk/mphil/MP6-15.pdf (accessed on 13 June 2018).

24. Tada, T.; Seo, T.; Higashimine, K.; Monzen, R. Ostwald ripening of rod-shaped $\alpha$-Fe particles in a Cu matrix. Mater. Lett. 2004, 58, 2007-2011.

(C) 2018 by the authors. Licensee MDPI, Basel, Switzerland. This article is an open access article distributed under the terms and conditions of the Creative Commons Attribution (CC BY) license (http://creativecommons.org/licenses/by/4.0/). 